\title{
Per capita gross domestic product and welfare of Gabonese households: A VAR model with exogenous hypothesis
}

\author{
Giscard ASSOUMOU-ELLA \\ CIREGED, Omar Bongo University, Gabon \\ LEAD, University of Toulon, France \\ g.assoumouella@gmail.com
}

\begin{abstract}
The objective of the study is to analyze the effect of per capita gross domestic product on the monetary and qualitative well-being of Gabonese households. As a result, we use a VAR model with exogenous hypothesis. The results show that wealth creation observed in Gabon from 1980 to 2017 does not promote the monetary well-being of households. Its effect on qualitative well-being is ambiguous. In addition, well-being responses to interaction of per capita GDP impulses with those of the labor market lead to proposing to the government the adoption of economic policies that change the structure of the economy. Indeed, the distribution of the fruits of growth should go through the creation of jobs, while the Gabonese economy is currently driven by the primary sector with few job opportunities. The results obtained by making predictions with the scenarios of deterioration of the labor market also militate for this proposal.
\end{abstract}

Keywords: per capita GDP; monetary and qualitative well-being; VAR model with exogenous hypothesis.

JEL Classification: I39; O11. 


\section{Introduction}

Debates on development policies have long been oriented towards the search of the economic growth because she would improve the well-being of the poor (Dollar and Kraay 2000, Bhagwati 2004). This beneficial effect had already been highlighted by some classical economists like Mill (1963) and Hayek (1994). According to Firebaugh and Beck (1994), the belief that growth benefits most people is the fundamental assumption of significant development. For Sachs (2005), liberalism and globalization have shown a remarkable ability to lift large numbers of people out of extreme poverty by promoting economic growth. However, some authors, like Stiglitz (2002), have challenged the "Washington Consensus" focused on growth. In addition, authors interested in human capacities and gender inequalities provide convincing critiques of the equation between GDP and well-being (Nussbaum and Sen, 1993; Dreze and Sen 1995; Sen, 1999, Nussbaum 2000). These criticisms are based on the debate concerning the measure of happiness.

Indeed, the traditional measure of well-being is based on the utility that is supposed to reflect the degree of satisfaction of individual preferences (Kahneman et al., 1997). As a result, the increase in income allows the satisfaction of preferences and leads to an increase in utility (well-being). The modern approach, on the other hand, integrates indicators relating to the analysis of subjective data collected from individuals, and reflecting the feeling of happiness declared (Frey and Stutzer, 2002). It also incorporates the "objective" indicators to measure quality of life and inequalities.

In this context, the present work consists of analyzing the effect of wealth production in Gabon from 1980 to 2017, measured by the per capita gross domestic product (per capita GDP), on the monetary and qualitative well-being of households taking into account gender inequalities. We make a distinction between per capita GDP and income effectively held by households that we approximate by consumption and access to the labor market.

The relevance of this study on Gabon is mainly based on the profile of its economy. Indeed, the country is an exporter of oil and other raw materials. As a result, fluctuations in world prices and quantities produced can lead to some volatility in per capita GDP, and consequently impact public policies that may affect household welfare. In addition, Gabon has long been ranked among the upper middle-income countries. However, unemployment and inequality are important in this country. Also, Gabon remains lagging behind in qualitative indicators of access to health, quality education and basic services such as water and electricity. Therefore, it seems legitimate to ask whether the creation of wealth really benefits Gabonese households. The ultimate interest is to provide an analytical basis that can give guidance to the government on the happiness of the population.

For econometric reasons on the number of variables that could be included in empirical model, the analysis takes into account the effect of the per capita GDP on the indicators of monetary well-being in a first group of estimates. The second group take into account the indicators of qualitative well-being. To do this, we estimate a VAR model with 
exogenous hypothesis (Paul, 1996) in which the world price of oil and the endowment of raw materials are considered exogenous. In a first step, we analyze the welfare responses following the impulses of the per capita GDP, and the combination of these with the impulses of the number of salaried workers (in percentage of the total population of the workers), and vulnerable jobs. In a second step, we create two scenarios. The first consists to reduce the number of salaried workers and to increase the number of vulnerable jobs. We combine these two scenarios with changes in per capita GDP. Thus, well-being forecasts incorporating these scenarios are made and compared to actual data.

The results of the first method show that the accumulated responses of monetary wellbeing to per capita GDP impulses are globally negative. The combination with the impulses of the number of salaried workers (as a percentage of the total population of workers) improves monetary well-being, while that with the impetus of vulnerable jobs deteriorates it. We also note that the effect of the per capita GDP on the qualitative welfare of Gabonese households is ambiguous. In addition, there is some improvement in qualitative well-being when combining the impulses of the per capita GDP with those of the number of salaried workers. On the other hand, there is deterioration by combining the impulses of per capita GDP and those of vulnerable jobs. For the second method, the model predicts that a decrease or increase in vulnerable jobs leads to lower inflation and higher consumption after one year. This result is achieved at the cost of more pronounced labor market deterioration for men compared to women. The scenario of decreasing salaried workers allows the model to predict a decline in access to health.

The work will be divided into two sections. In the first, we analyze the effect of per capita GDP on monetary well-being. In the second, we study the effect of per capita GDP on qualitative well-being.

\section{Effect of per capita GDP on household monetary well-being}

In several studies, it has been shown that economic growth improves household monetary well-being (Dollar and Kraay, 2000; Bhagwati, 2004). By testing the relationship between gross domestic product (GDP) and well-being in 62 Least Developed Countries (LDCs) from 1960 to 1980, Firebaugh and Beck (1994) conclude that the beneficial effects of growth are large and robust. In this context, the theoretical framework of reference in this section is based on the utilitarian approach of well-being, according to which the increase of income allows the satisfaction of preferences. It is also based on the "Washington consensus" arguing that economic growth is beneficial for households. Thus, we empirically test the assumption of a positive effect of the per capita GDP on the monetary well-being of Gabonese households. To do this, we begin with a brief summary of the recent literature on this issue, before proceeding with the estimates.

\subsection{Brief overview of recent literature}

Recent works focus on the analysis of the effect of growth on unemployment and its impact on monetary poverty (Kwasi Fosu, 2009; Howarth et al., 2016, Tabosa et al., 2016). 
With regard firstly to the labor market, Soylu et al. (2018) study the relationship between economic growth and unemployment in Eastern European countries for the period from 1992 to 2014 in panel data. The empirical context is inspired by Okun's Law. Their results show that a $1 \%$ increase in GDP would reduce the unemployment rate by $0.08 \%$ due to the Okun coefficient for the Eastern European countries and a co-integration between these macroeconomic variables. Carré and Drouot (2004) also analyze the same relationship by developing a theoretical model. Unlike Soylu et al. (2018), they incorporate technical progress in their analysis. Thus, inspired by the work of Mortensen and Pissarides (1998), they study the effect of economic growth on unemployment. Their results show that the "learning effect" can offset the effect of creative destruction induced by the acceleration of technological change on unemployment. Moreover, the relationship between wage dispersion and growth may be non-monotonic. In this context, it could be used to explain the compression/expansion of wages observed in time series data.

Secondly, as regards the effect on monetary poverty, the role played by inequalities in income distribution is highlighted. Thus, Tabosa et al. (2016) analyze the impact of economic growth and income inequality on poverty in Brazil between 1981 and 2013. The model is a dynamic panel estimated using the generalized moments (GMM) developed by Blundell-Bond (1998). Their results indicate that economic growth policies that promote income growth while integrating the decrease of income inequalities are more effective for fighting against poverty in Brazil. This conclusion is not the same concerning those that focus solely on increasing levels of income. Unlike Tabosa et al. (2016) whose study focuses on a particular country, Kwasi Fosu (2009) takes a comparative approach between countries. It examines the extent to which inequality affects the impact of growth on poverty rates in sub-Saharan Africa (SSA) relative to other countries. The study is based on a panel of 86 countries between 1977 and 2004 . He finds that the impact of GDP growth on poverty reduction is a decreasing function of the initial inequality of income distribution. The impacts are similar for SSA countries and others, so that there is considerable disparity in the responsiveness of poverty to income growth, based on inequality. Nevertheless, income elasticity-growth is much lower in SSA countries; which implies a relatively weak response from poverty reduction to growth. In a more recent paper from 2017, the same author presents global comparative data on the transformation of economic growth into poverty reduction in developing countries. Emphasis is also placed on the initial level of income inequality in each country. The analysis begins in the mid-1990s, when economic growth in these countries was relatively strong. He concludes that while in most countries, economic growth was the main factor in reducing or increasing poverty, inequality played a crucial role in many countries. Indeed, high levels of initial inequality limit the effectiveness of growth in reducing poverty. A gradual increase in inequality directly increases poverty for a given level of economic growth. In this context, the author concludes that it seems appropriate to pay particular attention to the reduction of inequalities in certain countries where the distribution of income is particularly unequal. In this same line, Howarth et al. (2016) analyze the relationship between income and well-being in the United States. Unlike Tabosa et al. (2016) and Kwasi Fosu $(2009 ; 2017)$, the authors construct the indicators based on a classic utilitarian framework and empirical evidence. They find that per capita 
after-tax incomes increased by $1.7 \%$ per year between 1979 and 2011 . However, a growth rate of $1.2 \%$ per annum appears when income is adjusted to take into account social costs of inequality.

\subsection{Empirical evaluations}

In the continuity of Sims (1980), we estimate, like Paul (1996), a VAR model with hypothesis of exogeneity in which the world price of oil and the endowment of raw materials are considered exogenous. Indeed, Gabon is a "price taker" on the world oil market and the presence of raw materials is a natural factor that the economy can not change. In addition, Granger causality tests (1969) show that national variables do not cause the world price of oil and the endowment of raw materials (see Table 1).

Table 1. VAR Granger Causality/Block Exogeneity Wald Tests

\begin{tabular}{|l|l|l|l|}
\hline $\begin{array}{l}\text { Dependent } \\
\text { variables }\end{array}$ & PIBH & RENT & OIL PRICE \\
\hline PIBH & ----- & 0.0062 & 0.0744 \\
\hline RENT & 0.6003 & --- & 0.8876 \\
\hline OIL PRICE & 0.5328 & 0.3235 & --- \\
\hline
\end{tabular}

Thus, these variables are used as exogenous controls, with Gabon being heavily endowed with natural resources. As a result, we have the empirical equation below:

$Y_{t}=\Phi_{1} Y_{t-1}+\cdots+\Phi_{p} Y_{t-p}+\emptyset X_{t}+\varepsilon_{t}$

$Y_{t}$ represents the vector of $\mathrm{n}$ endogenous variables of dimension $(n \times 1) . t$ is the time index and $\mathrm{p}$ the number of lags. The $\Phi_{1}, \ldots \Phi_{p}$ represent the matrices of dimension $(n \times$ $n$ ) including the coefficients to estimate. $X_{t}$ is the vector of deterministic and exogenous variables with $\emptyset$, the matrix of coefficients associated to this vector. Finally, $\varepsilon_{t}$ is a vector of innovations of dimension $(n \times 1)$. We perform the pre-estimate stationarity test (Augmented Dickey-Fuller and Phillips Perron) to avoid the fallacy regression problem. The conditions for a Johansen co-integration test are not occurred. Finally, we carried out the following post-estimation tests: Portmanteau and LM autocorrelation residue tests, VAR stability and LM heteroscedasticity test. The optimal number of lags is chosen based on the information criteria.

Method 1: accumulated responses of monetary well-being to per capita GDP impulses

We make six estimates. In the first (1), the vector of endogenous variables is composed of per capita GDP, unemployment of men (CHOMAGEH), vulnerable jobs of men (VULNERABLEH), the number of male salaried workers (WAGEH), the ratio of the rate of male / female employment (RATIO), household consumption (CON) and inflation (INF). The vector of deterministic and exogenous variables includes the constant, the world price of oil and the endowment of raw materials. It is the same in all models. The second estimate (2), for its part, includes in the endogenous: the per capita GDP, the unemployment of women (CHOMAGEF), the vulnerable jobs of women (VULNERABLEF), the number of women salaried workers (WAGEF), RATIO, CON and INF. The third (3) and fifth (5) estimates contain the same endogenous as the first 
estimate, but the per capita GDP is replaced respectively by its interaction with the number of salaried workers (per capita GDP $\times$ WAGE) and finally with EMPLOIV (per capita GDP $\times$ EMPLOIV). The fourth (4) and sixth (6) estimates contain the same endogenous as the second. As in the previous case, per capita GDP is respectively replaced by per capita GDP $\times$ WAGE, and per capita GDP $\times$ EMPLOYMENT. Interaction variables show the combined effect of per capita GDP and the quality of the labor market. Per capita GDP $\times$ WAGE measures the combined effect of the real per capita GDP and WAGE impulses on monetary well-being by sex. Per capita GDP $\times$ EMPLOYMENT, for its part, measures the effect on monetary well-being of the interaction of real per capita GDP impulses and vulnerable jobs. Data are from the World Bank (online database: World Development Indicators).

(1)

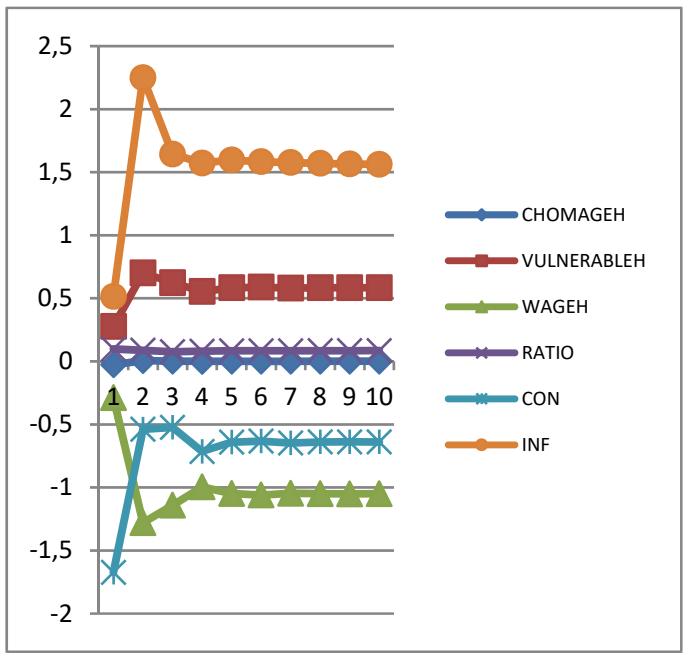

(2)

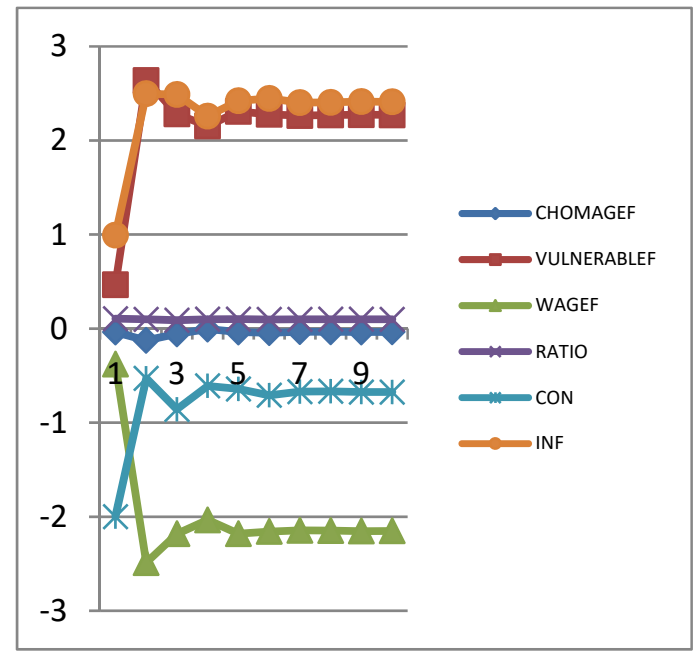

The results of estimates (1) and (2) show that per capita GDP impulses lead to a sustained increase in: inflation, the number of vulnerable jobs and the participation of men and women in the labor market. The increase in vulnerable jobs is greater for women. There is also a steady decline in the number of salaried workers. It is more important in women. There is also a lasting decline in unemployment and household consumption. Thus, the accumulated responses of monetary well-being to per capita GDP impulses are globally negative. In fact, the decrease in unemployment is accompanied by an increase in vulnerable jobs and a fall in the number of salaried workers. Combined with rising inflation, the decline in household consumption is the result. Even though there is an increase in the access of men and women to the labor market, which reflects a decrease in inequalities. It can only be achieved by increasing the number of vulnerable jobs for women and, consequently, a greater decline in the number of female salaried workers in the latter, compared to that observed for men. In the end, the wealth creation observed in Gabon between 1980 and 2017 does not bring about the monetary well-being of households. In this context, we want to know what would happen if it was accompanied by an increase in the number of salaried workers; symbol of a more attractive job market. This is shown by the results of the estimates (3) and (4) below. 
(3)

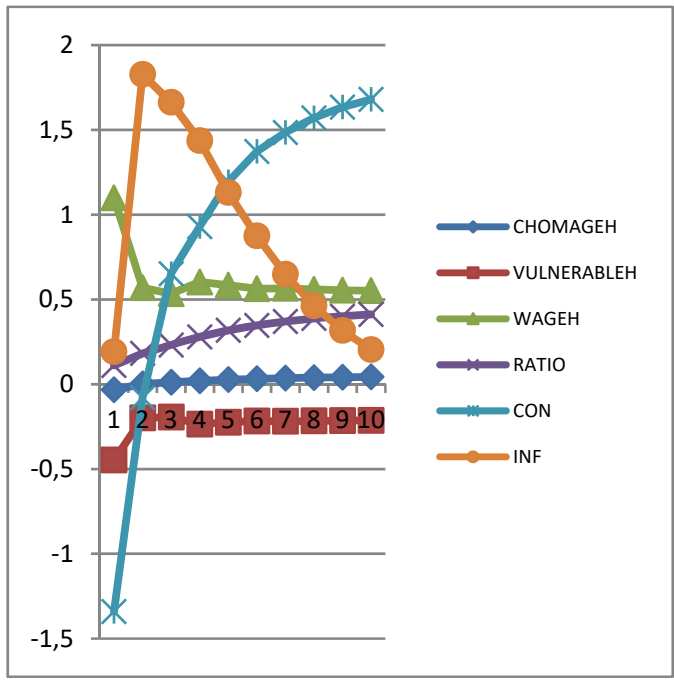

(4)

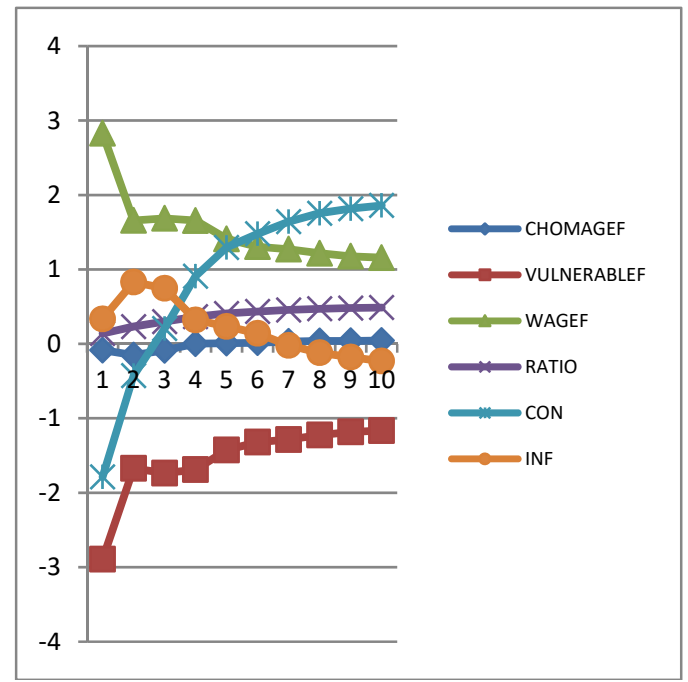

The impulses of the per capita GDP combined with those of the number of salaried workers lead to a sustainable increase in household consumption. This combination also leads to an increase in the number of salaried workers in women. There is also a larger decline than in the estimates (1) and (2) of gender inequality in terms of access to the labor market. Vulnerable jobs are also falling. In addition, there is a decrease in unemployment in the first two years, and a relative increase in the following years, because it is around zero. The rise in inflation is very pronounced in the first two years. It gradually decreases while remaining above zero. Thus, the results of estimates (3) and (4) reflect some improvement in household monetary well-being and a male-female catch-up, compared to the results of estimates (1) and (2). Let's take a look at what is happening by combining the impulses of the per capita GDP with those of the vulnerable jobs; symbol of a deterioration of the labor market. This is the subject of estimates (5) and (6) below.

(5)

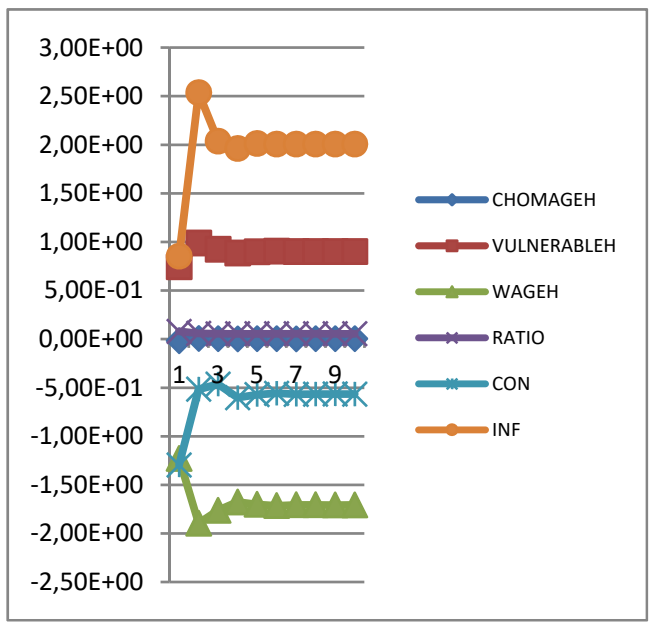

(6)

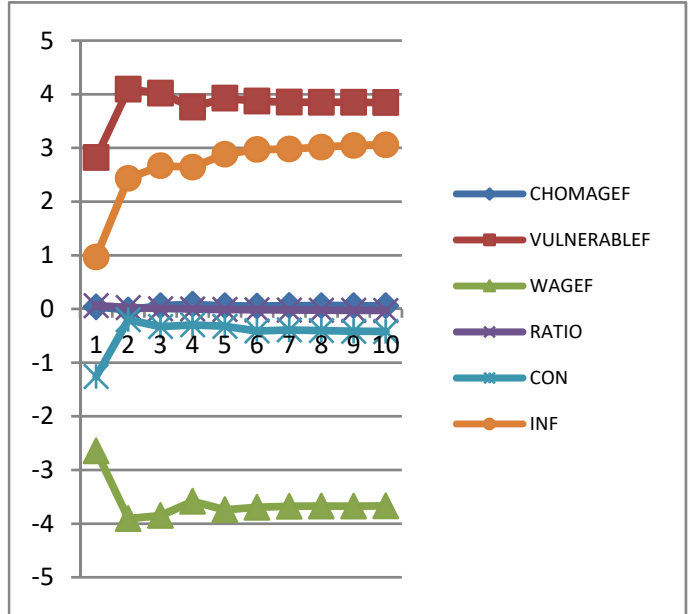


There is a decline in the number of salaried workers more pronounced among women, compared to that observed among men. It is also larger relative to estimates (1) and (2). There is also a decline in household consumption. Unemployment and male-female labor market access are increasing, but remain around zero. Vulnerable jobs increase more in women. Finally, inflation is also rising. Thus, contrary to estimates (3) and (4), a wealth creation that is accompanied by a deterioration of the labor market has negative consequences on the monetary well-being of households.

\section{Method 2: Scenarios and Forecasts}

The first method was to combine the per capita GDP impulses with the number of salaried workers, and vulnerable jobs in a first step. In a second step, the goal is to measure the response of the well-being indicators. Concerning the second method, we still estimate the equation (1)', but the goal is to make the predictions by creating the scenarios. We then compare these forecasts with the actual data. The purpose is to see the effect of the decline in the number of salaried workers and the increase in vulnerable jobs on household welfare. To do this, we create different scenarios. We see what would have happened in the evolution of monetary well-being if these scenarios had occurred. In the first scenario, it is assumed that the evolution of the per capita GDP was combined with an annual decline in the number of salaried workers by $10 \%$ between 2008 and 2017. In the second, it is assumed that the evolution of the per capita GDP was combined with an annual increase in vulnerable jobs by $10 \%$ between 2008 and 2017 . Thus, we base ourselves respectively on the results (7), (8), (9) and (10) below. These results generally show that a fall in the number of salaried workers or an increase in vulnerable jobs leads to a fall in inflation and a rise in consumption after one year. This is only possible at the cost of a more pronounced labor market decline for men than for women. As a result, the forecasts of the effect on monetary well-being seem ambiguous.

Scenario 1: per capita GDP interaction with an annual decline in the number of salaried workers by $10 \%$ from 2008 to 2017 
(7)
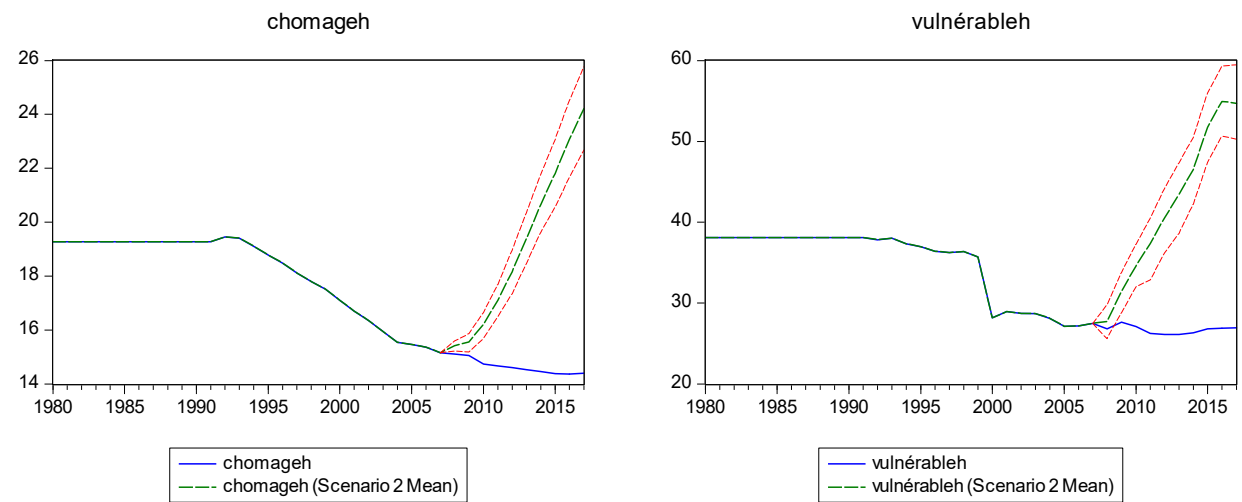

wageh

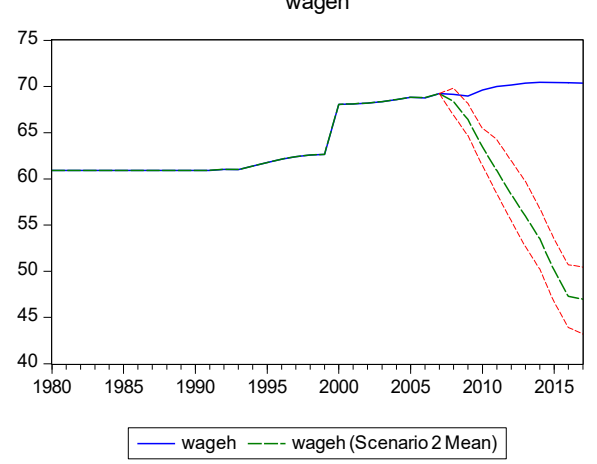

ratio

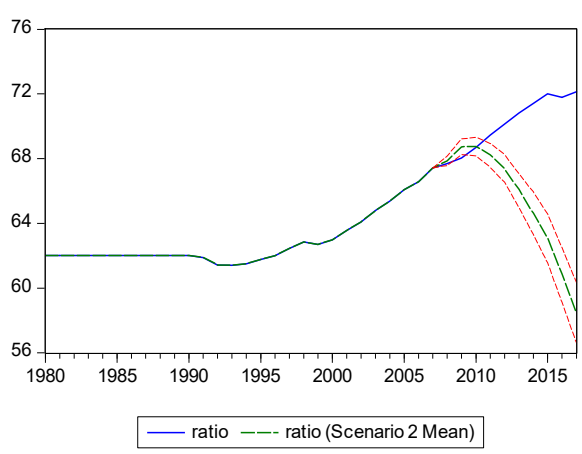

con

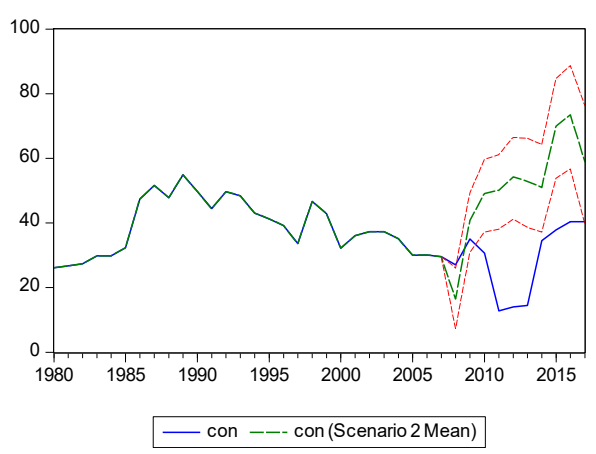

inf

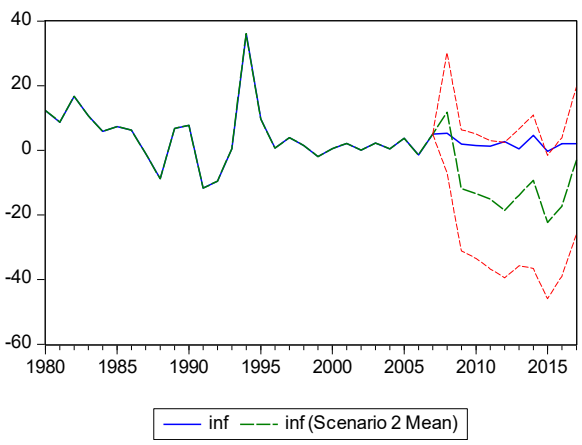

The result (7) compares the real data with the forecasts (Scenario 2 Mean) of the monetary well-being of men. Following a decline in the number of salaried workers by $10 \%$ between 2008 and 2017, the model predicts, compared to the evolution of real data, an increase in male unemployment, an increase in men's vulnerable jobs, a fall in the number of salaried workers in men, a decrease in gender inequalities in access to the labor market in the first two years followed by an increase in inequality, a decline in household consumption in the first year followed by an increase, and finally an increase 
in inflation the first year followed by a decline. Thus, we find that the lasting decline in the level of inflation after the second year allows the model to predict a sustainable increase in household consumption over the same period. This is only possible at the cost of deterioration in the labor market (rising unemployment and vulnerable jobs for men, and a decline in the number of male salaried workers) and an increase in inequality access to the labor market.

(8)
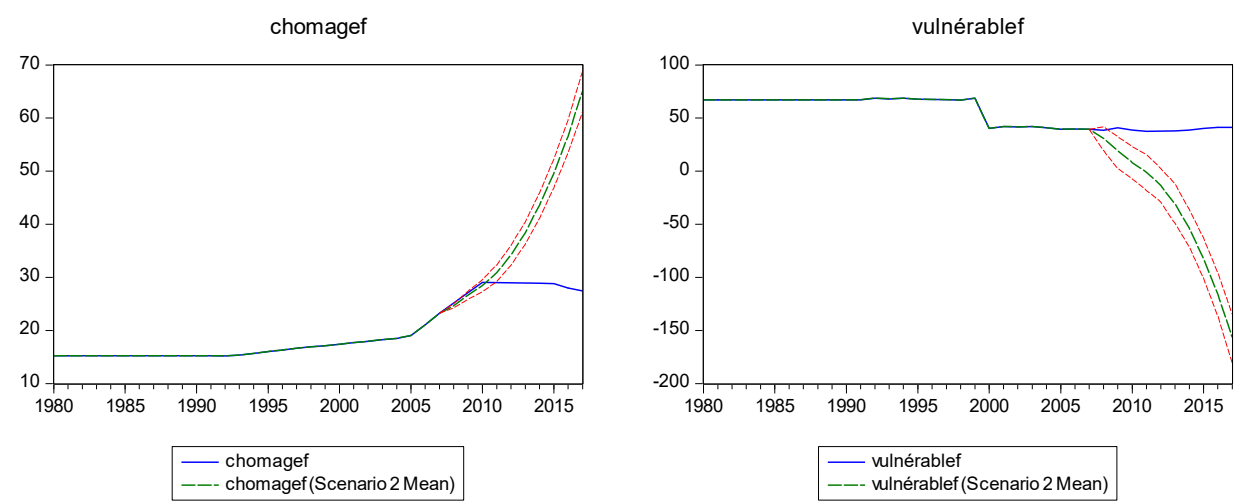

wagef

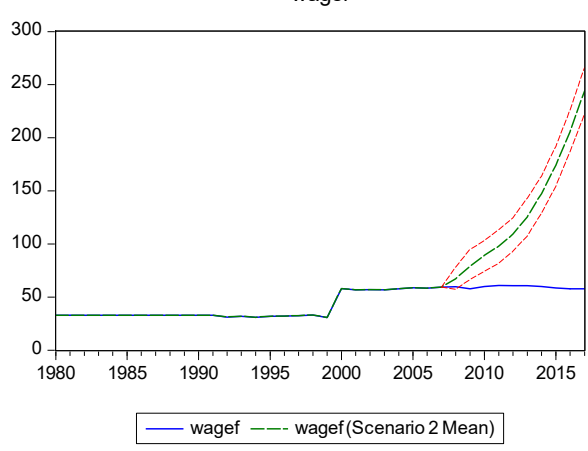

ratio
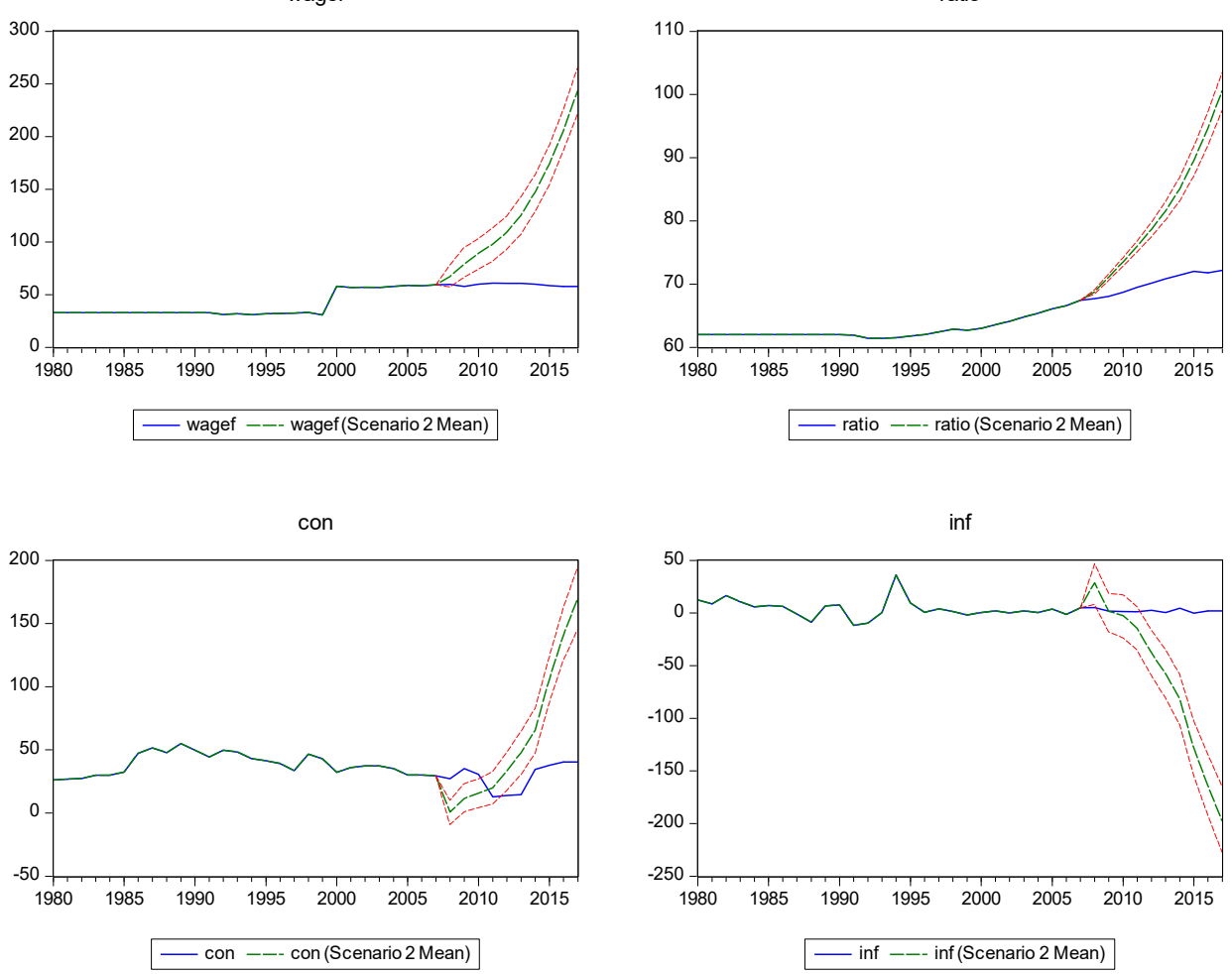
In the estimate (8), the forecasts of consumption and inflation are the same as in the estimate (7). There is also a rising forecast of female and male unemployment compared to actual data. However, the level of vulnerable jobs is declining in the latter. There is also a certain increase in the number of salaried workers.

Scenario 2: per capita GDP interaction with an annual increase of vulnerable jobs by $10 \%$ from 2008 to 2017

(9)
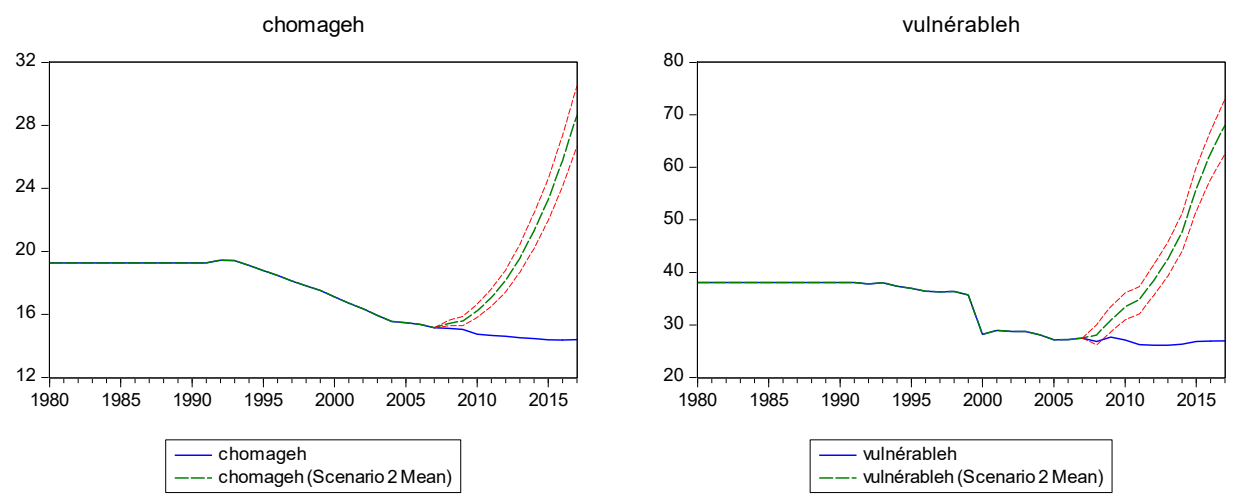

- chomageh

wageh

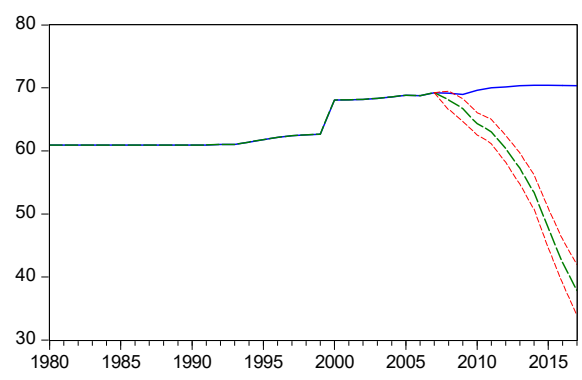

ratio

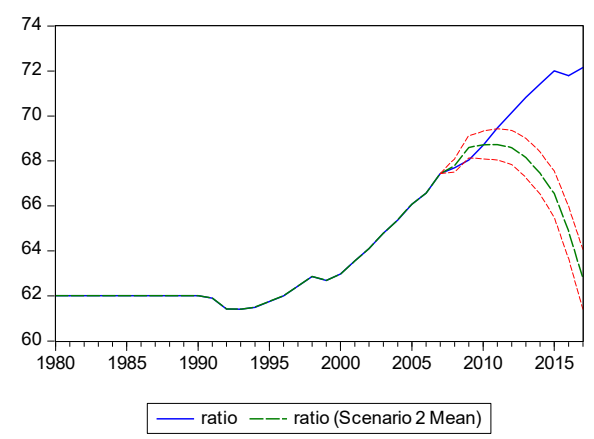

con

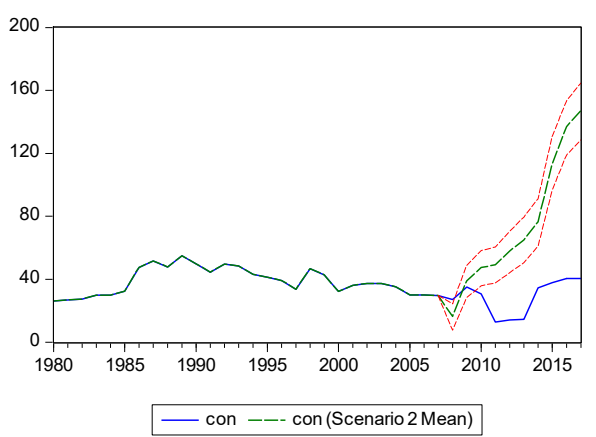

inf

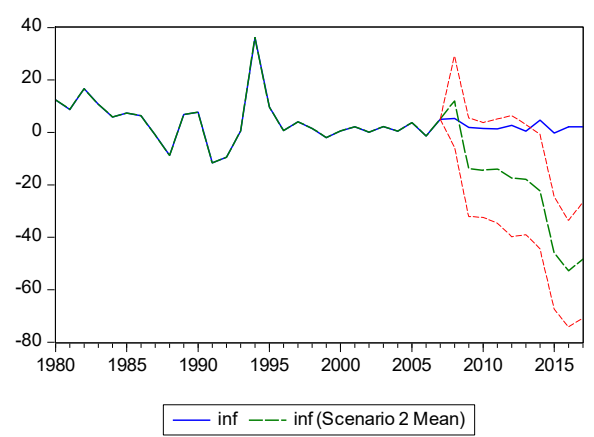


According to (9), as in the case of the fall in wages ((7) and (8)), the increase in vulnerable jobs has the same consequences for consumption and inflation. There is also an increase in unemployment and vulnerable jobs for men, and a decline in the number of salaried workers.

(10)
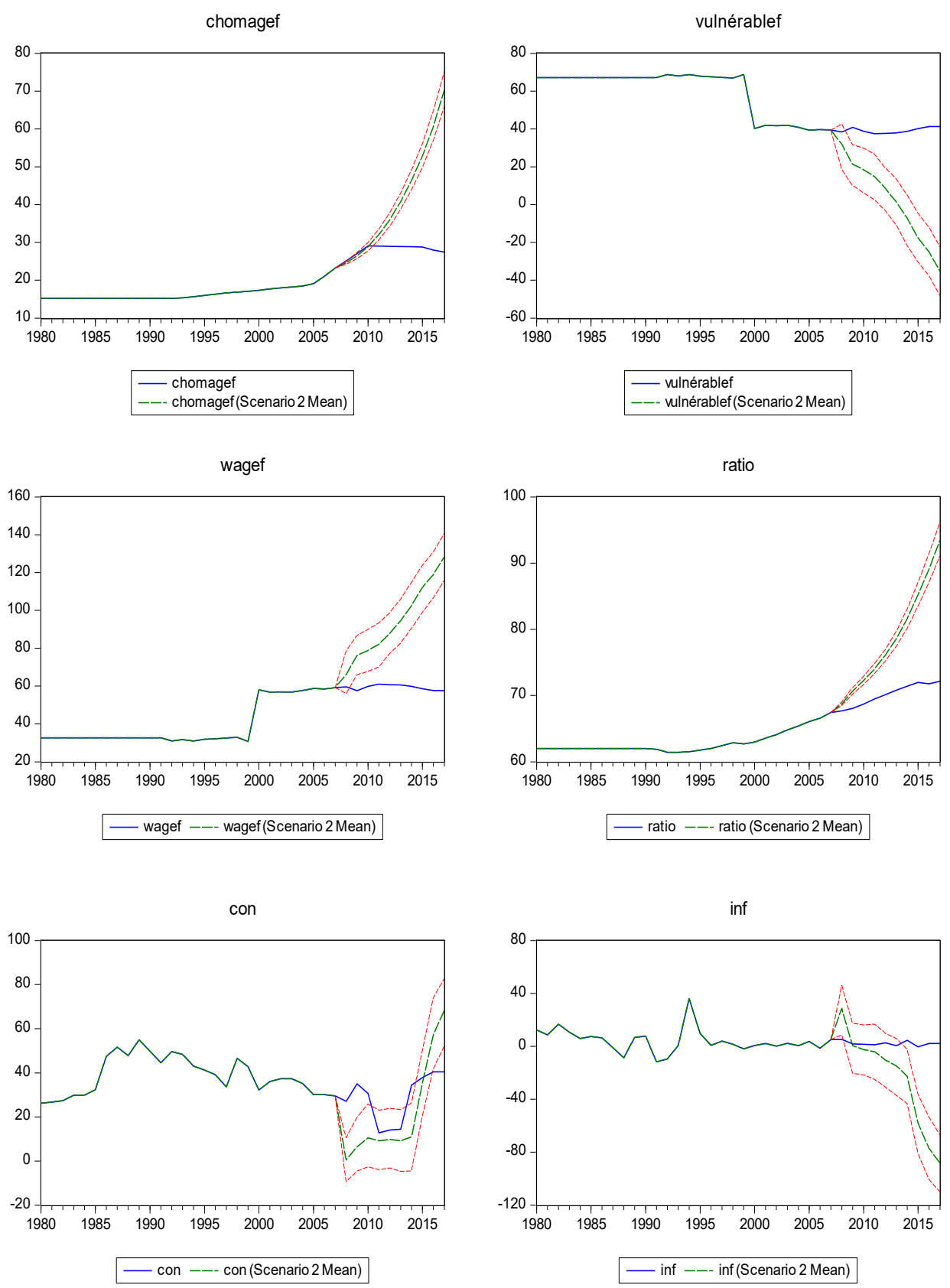
In the case of women (10), the forecasts are very similar to those of the case (8). Indeed, the model predicts a rise in female unemployment and the number of female employees, but also a decline in vulnerable jobs. The behavior of consumption is slightly different. Indeed, it remains permanently down and only increases in recent years.

\section{Effect of per capita GDP on the qualitative well-being of households}

In the first section, the effect of per capita GDP on household welfare is analyzed solely by the income approach. However, convincing critiques of the GDP-well-being equation have been made by some authors interested in human capacity (Nussbaum and Sen, 1993, Dreze and Sen, 1995, Sen, 1999). For the latter, income is not a welfare, but rather a resource that provides the ability to buy well-being. As a result, development strategies should not only focus on increasing incomes, but also on "capabilities". For some gender and development specialists, it would be unrealistic to assume that growth benefits men and women in the same way. Indeed, the sources of well-being of women and men may differ (Blumberg 1995, Bose and Acosta-Belen 1995, Parpart et al., 2000). Thus, based on the theoretical framework that the income makes it possible to buy well-being, the object of this section is to measure the capacity of the per capita GDP to allow the Gabonese households to buy qualitative well-being; while taking into account the state of the labor market. To do this, we begin with a brief review of the literature before proceeding with empirical checks.

\subsection{Brief overview of recent literature}

According to Sen (1999), well-being should not only integrate income and resources, but also human development and "capabilities". It is in this perspective that Gopalakrishna and Rao (2012) explore the link between economic growth and human development (HDI) in India. Their results indicate convergence trends rather than differences in HDI during the liberalization period. Indeed, a positive relationship between economic growth and human development has been highlighted by these authors. However, their results also show that health expenditure has not had a significant influence on human development. In addition, the dummy variable which is an indicator of the initial level of development is significant in the further development of states. This suggests that public spending on health and education plays an important role in human development. Thus, the authors conclude that the government should play an active role in resolving all forms of inequality between states in the field of human development; including access to public health, education, food, clothing, housing and a decent standard of living. Brady et al. (2007) analysed, for their part, the impact of growth on well-being measured by caloric consumption, the probability of infant survival, the probability of survival of one in five years, the life expectancy of women and men's life expectancy. Thus, unlike Gopalakrishna and Rao (2012), the authors extend the analysis to other aspects of human capacities, while making a comparison between different countries. First, they find that GDP has significant positive effects on calorie consumption, women's life expectancy and men's life expectancy. Second, their results show that GDP has no strong effects on infant survival probability and survival probability from one year to five. As a result, they conclude that there are serious limits to focusing exclusively on economic growth in order to improve well-being in LDCs. 


\subsection{Empirical evaluations}

Method 1: Accumulated responses of qualitative well-being to per capita GDP impulses

The estimates (11), (12) and (13) respectively represent the accumulated responses of the variables representing the qualitative living conditions to the impulses of the per capita GDP, per capita GDP $\times$ WAGE and finally per capita GDP $\times$ EMPLOIV. The choice is guided not only by the economic theory of "capabilities" but also by the availability of data. These variables can be divided into two groups. The first concerns access to health. It consists of: infant mortality (MORTINF), vaccination of measles in children aged 12 to 23 months (IM), vaccination against diphtheria and whooping cough in children aged 12 to 23 months (IMDPT) and newborns protected against tetanus (TETANUS). The second, as for him, integrates the other accesses. It is composed of: access to electricity in $\%$ of the population (ACCESELT), number of people using at least basic water services as $\%$ of the total population (PUWST), CO2 emissions (CO2), and the proportion of seats occupied by women in national parliaments (PARLIAMENT). In this second group, we want to take into account other human capacities. This concerns the ability of households to have access to electricity and water, but also to breathe an unpolluted air. Finally, we take into account women's access to parliamentary seats. The estimated empirical equation is identical to (1)'.

(11)

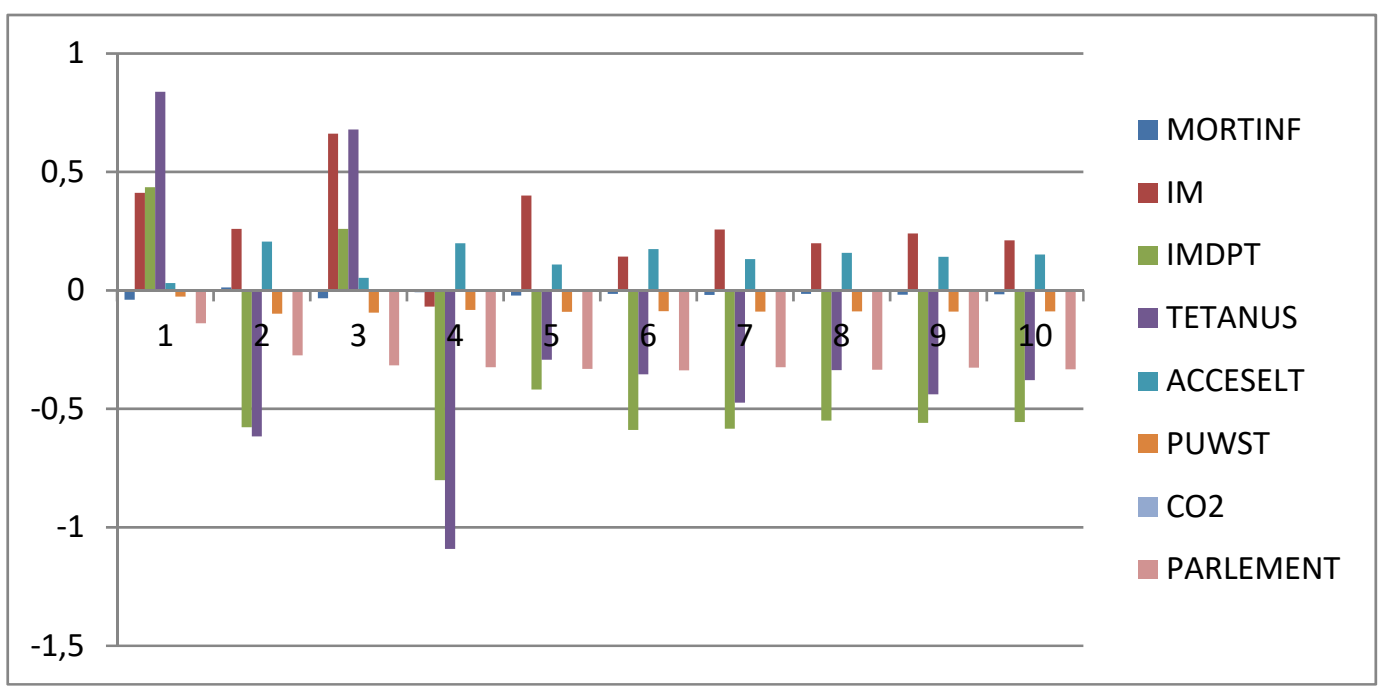

The results of the estimation (11) show that the accumulated responses of IM (except for the fourth year) and ACCESLT to per capita GDP impulses are lastingly positive and significant. Infant mortality is also declining, but remains around zero. While there may be an increase in IMDPT and TETANUS in the first year, these variables subsequently have a downward trend. Downtrends are also noted for PUWST, CO2 and PARLIAMENT. Ultimately, the effect of the per capita GDP on the qualitative welfare of Gabonese households is ambiguous. In fact, although there may be a slight decrease in infant mortality, and an increase of children immunized against measles, there is also a 
lasting decline after the first year of immunization against diphtheria and pertussis, and tetanus. While the creation of wealth increases the number of people with access to electricity, it also decreases access to water and the number of women parliamentarians. The estimate (12) below shows whether households are able to buy qualitative well-being when the increase in per capita GDP goes hand in hand with that of salaried workers.

(12)

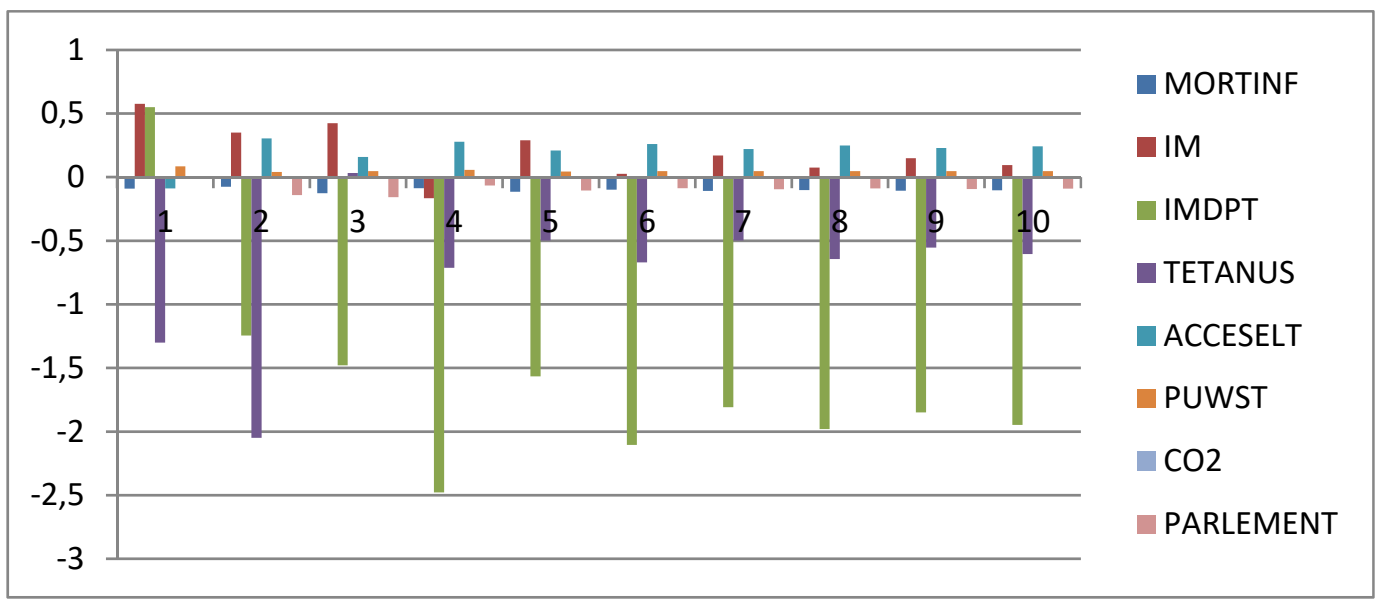

There is a larger decline in infant mortality than in the case (11). There is also an increase in IM, except for the fourth year. Access to electricity is more important than in the previous case. Another significant difference is the access to water. The number of women parliamentarians is still declining, but the trend is less important than in the case (11). The other answers are globally identical to the previous case. Thus, there is some improvement in qualitative well-being when one combines the impulses of the per capita GDP and those of the number of salaried workers, compared to the case (11). Now let's see what happens when the evolution of the per capita GDP goes hand in hand with a deterioration of the labor market.

(13)

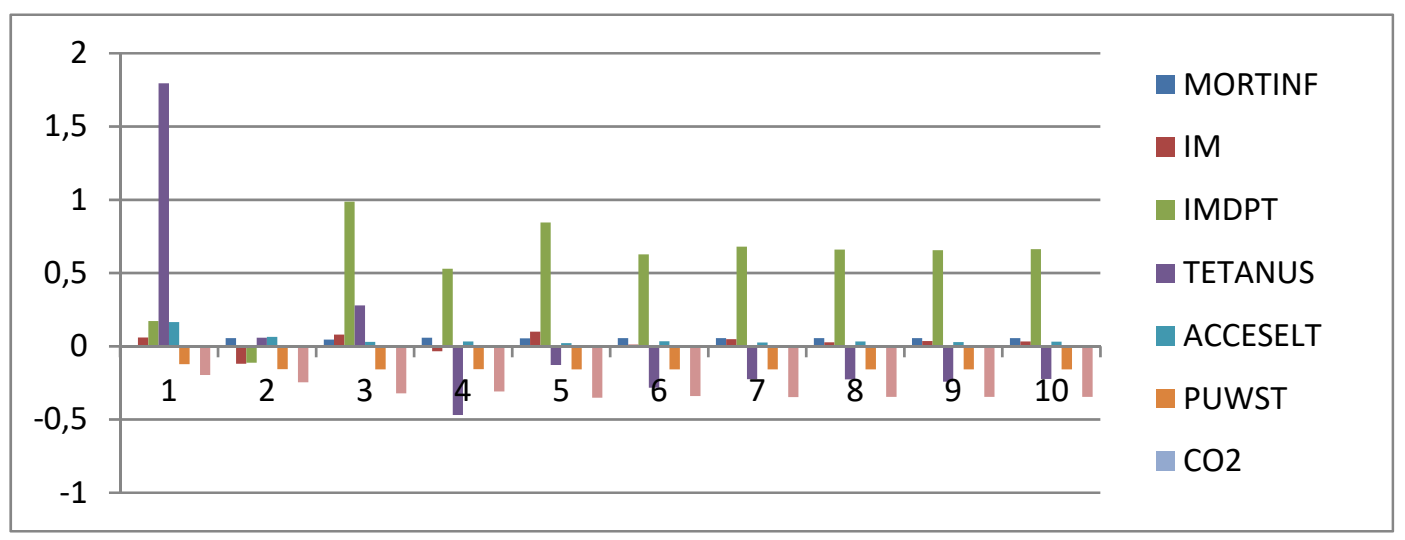


Unlike case (12), the result (13) shows a sustained increase in infant mortality, a decrease in access to water, a smaller increase in access to electricity and a larger decline in number of women parliamentarians. The increase in IM is also less important, while finding negative values in the second and fourth years. In this context, it can be generally concluded that the combination of per capita GDP impulses and those of vulnerable jobs degrades the qualitative well-being of Gabonese households.

Method 2: Scenarios and forecasts

As in the case of monetary well-being, we create scenarios of declining numbers of salaried workers and increasing vulnerable jobs. We combine them with the evolution of the per capita GDP to see the effect on the qualitative well-being of Gabonese households.

Scenario 1: per capita GDP interaction with annual decline in the number of salaried workers by $10 \%$ from 2008 to 2017

(14)
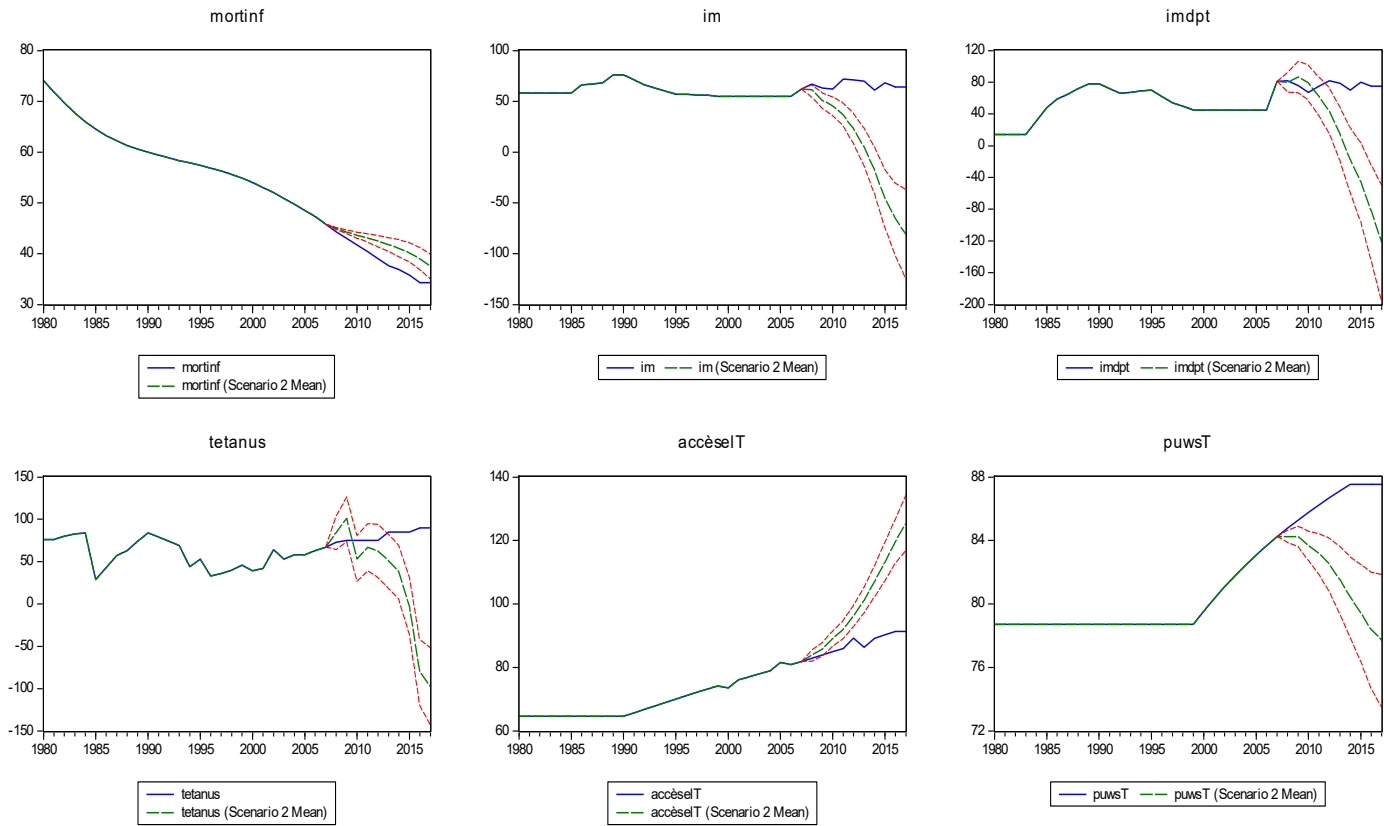

co2
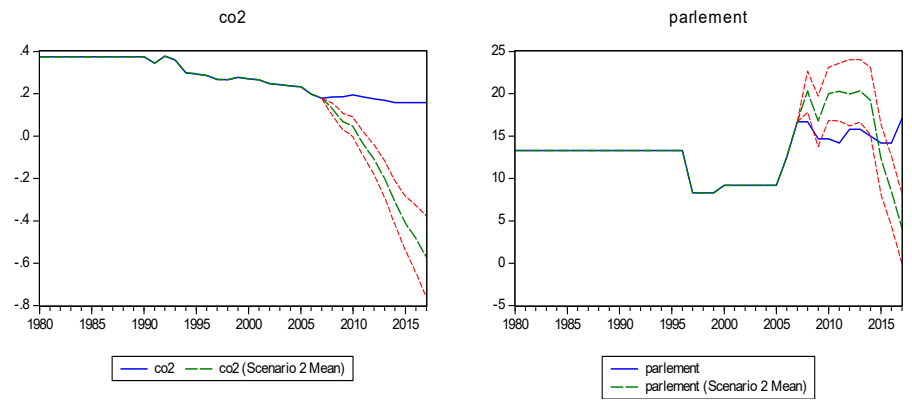
According to (14), the interaction of per capita GDP with an annual decline in the number of salaried workers of $10 \%$ between 2008 and 2017 leads to an increase in infant mortality, a drop in the number of children immunized against measles, diphtheria and pertussis, and tetanus, after a slight increase in the first year for the last two cases. There is also a decline in the number of people using at least basic water services as $\%$ of the population. In addition, the number of women parliamentarians increases first and then decreases thereafter. Finally, there is an increase in access to electricity as \% of the population and a decrease in $\mathrm{CO} 2$ emissions. Thus, lower salaried workers degrade access to household health. Now let's look at the model's forecasts in the event of an annual increase of $10 \%$ in vulnerable jobs.

Scenario 2: per capita GDP interaction with an annual increase of vulnerable jobs by $10 \%$ from 2008 to 2017

(15)

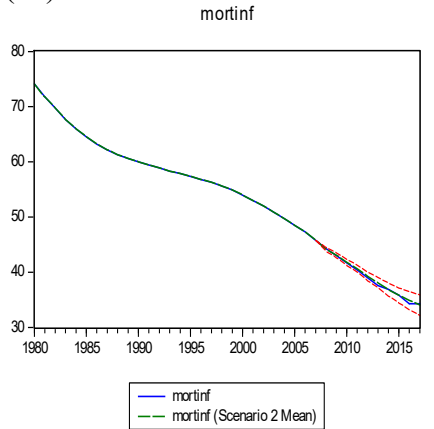

tetanus

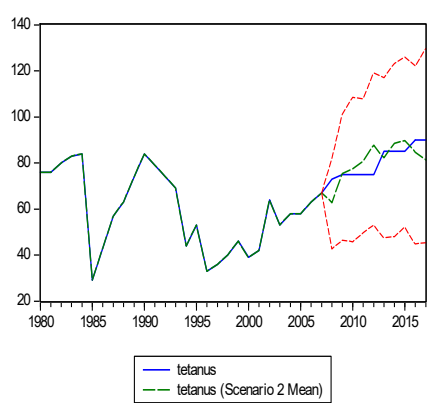

co2

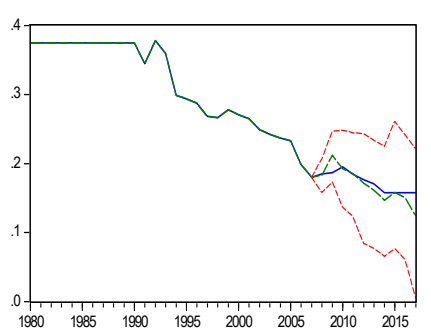

- $\mathrm{co2}--\mathrm{co2}$ (Scenario 2 Mean) im

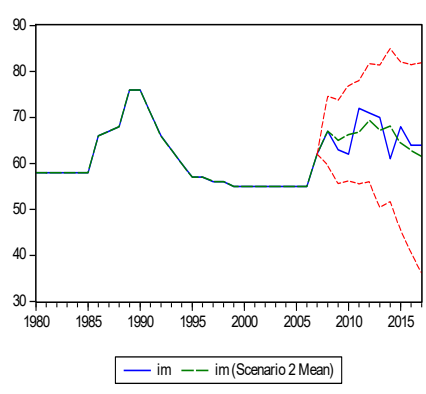

accèselT

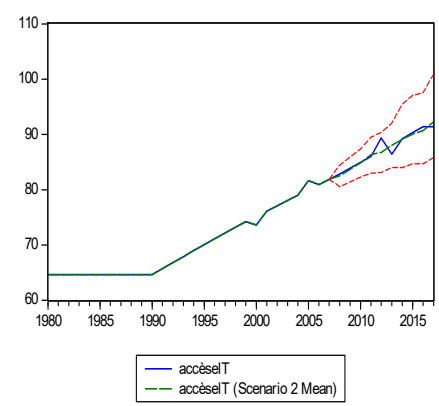

parlement

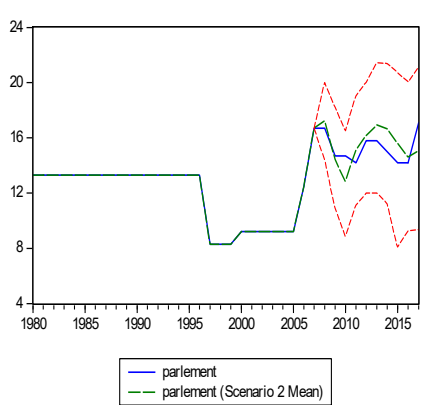

imdpt

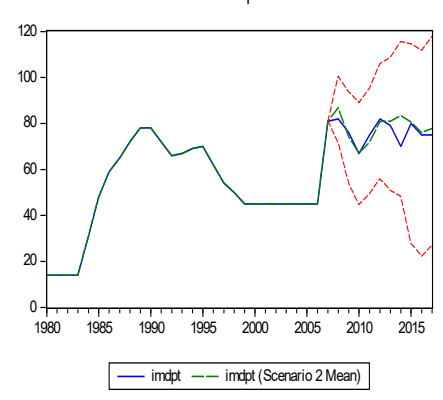

puwsT

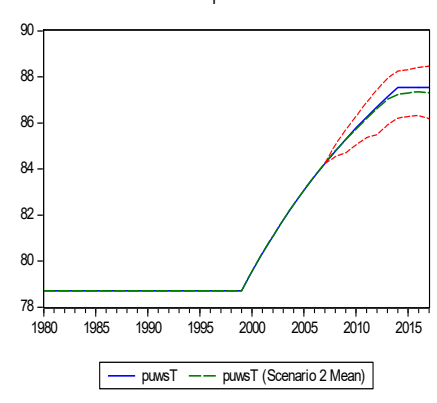


According to (15), the predicted data of infant mortality remain around real data. The predictions of vaccination are non-linear. There is a clear decrease in immunization against measles and tetanus in the first year compared to actual data. The values of access to electricity and water generally remain around real values. Predictions of $\mathrm{CO} 2$ emissions and the number of women parliamentarians may also be higher or lower than actual data.

\section{Conclusion and recommendations}

In summary, the results of the first method show that the accumulated responses of the monetary well-being variables to the per capita GDP impulses are globally negative. Thus, we can deduce that the wealth creation observed in Gabon between 1980 and 2017 does not promote the monetary well-being of households. This result should lead governments to adopt economic policies to change the structure of the economy which is mainly driven by the primary sector that creates little job.

The distribution of the fruits of growth should go through the improvement of the labor market. This is demonstrated by the combination of per capita GDP impulses with the number of salaried workers and vulnerable jobs. In fact, we have an improvement in monetary well-being in the first case, and deterioration in the second. We also note that the effect of the per capita GDP on the qualitative welfare of Gabonese households is ambiguous. This result reinforces the fact that wealth creation does not benefit households overall. As in the case of monetary well-being, there is some improvement in qualitative well-being when combining the per capita GDP impulses with the number of salaried workers. On the other hand, deterioration is generally observed by combining the impulses of the per capita GDP with those of the vulnerable jobs.

For the second method, the model predicts that a decrease or increase in vulnerable jobs leads to lower inflation and higher consumption after one year. This result is achieved at the cost of a more pronounced labor market access decline for men compared to women. As a result, the forecasts of monetary well-being seem ambiguous. On the other hand, the scenario of declining number of salaried workers allows the model to predict deterioration in access to health.

References

Bhagwati, J., 2004. In defense of globalization. New York: Oxford University Press.

Blumberg, R.L., 1995. Engendering wealth and well-being. Boulder, CO: Westview. 
Blundell, R. and Bond, S., 1998. Initial conditions and moment restrictions in dynamic panel data models, Journal of Econometrics, Vol. 87, No. 1.

Bose, C.E., 1995. Acosta-Belen E. Women in the Latin American development process. Philadelphia: Temple University Press.

Brady, D., Kaya, Y. and Beckfield, J., 2007. Reassessing the Effect of Economic Growth on Wellbeing in Less-developed Countries, 1980-2003, Studies in Comparative International Development, Vol. 42, pp. 1-35.

Carré, M. and Drouot, D., 2004. Pace versus type: the effect of economic growth on unemployment and wage patterns, Review of Economic Dynamics, No. 7, pp. 737-757.

Dollar, D., Kraay, A., 2000. Growth is good for the poor. Washington DC: World Bank.

Dreze, J. and Sen, A., 1995. India: economic development and social opportunity. Delhi: Oxford University Press.

Frey, B. and Stutzer, A., 2002. What Can Economics Learn From Happiness Research?, Journal of Economic Literature, vol. 40, pp. 402-435.

Firebaugh, G. and Beck, F.D., 1994. Does economic growth benefit the masses? Growth, dependence, and welfare in the third world, Am Sociol Rev, 59, pp. 631-53.

Gopalakrishna, B.V. and Rao, J., 2012. Economic Growth \& Human Development: The Experience of Indian States, Indian Journal of Industrial Relations, Vol. 47, No. 4, pp. 634-644.

Granger, C.J., 1969. Investigating Causal Relations by Econometric Models and Cross-spectral Methods, Econometrica, 37(3), pp. 424-438.

Hayek, F.A., 1994. The road to serfdom. Chicago: The University of Chicago Press.

Howarth, R.B., Kennedy, K., 2016. Economic growth, inequality, and well-being, Ecological Economics, vol. 121, pp. 231-236.

Kahneman, D., Wakker, P.P. and Sarin, R.K., 1997. Back to Bentham? Explorations of Experienced Utility, Quarterly Journal of Economics, vol. 112, pp. 375-405.

Kwasi Fosu, A., 2009. Inequality and the Impact of Growth on Poverty: Comparative Evidence for Sub-Saharan Africa, The Journal of Development Studies, vol. 45, No. 5, pp. 726-745.

Kwasi Fosu, A., 2017. Growth, inequality, and poverty reduction in developing countries: Recent global evidence, Research in Economics, Vol. 71, pp. 306-336.

Mill, J.S., 1963. Utilitarianism. Toronto: University of Toronto Press.

Mortensen, D.T. and Pissarides, C.A., 1998. Technological progress, job creation and job destruction, Review of Economic Dynamics, pp. 733-753.

Nussbaum, M., 2000. Women and human development. New York: Cambridge University Press.

Nussbaum, M. and Sen, A., 1993. The quality of life. Oxford: Clarendon.

Paul, S., 1996. Defence Spending and Unemployment Rates: An Empirical Analysis for the OECD, Journal of Economic Studies, 23(2), pp. 44-54.

Parpart, J.M., Connelly, P. and Barriteau, V.E, 2000. Theoretical perspectives on gender and development. Ottawa: IDRC.

Sachs, J.D., 2005. Can extreme poverty be eliminated? Sci Am, 22.

Sen, A., 1999. Development as freedom. New York: Anchor.

Sims, C.A., 1980. Macroeconomics and Reality, Econometrica, 48(1), pp. 1-48. 
Soylu, Ö.B., Çakmak, I. and Okur, F., 2018. Economic growth and unemployment issue: Panel data analysis in Eastern European Countries, Journal of International Studies, 11(1), pp. 93-107.

Stiglitz, J.E., 2002. Globalization and its discontents. New York: Norton.

Tabosa, F.J.S., de Carvalho Castelar, P.U. and Irffi, G., 2016. Brazil, 1981-2013: the effects of economic growth and income inequality on poverty, CEPAL Review No. 120. 